\title{
The Comparative Research of Female Volleyball Game Rhythm for Guangdong and Tianjin in 2012-2013 National Women Volleyball League Finals
}

\author{
Shi Hong Pu and Ben Song Xiao*
}

Institute of P.E, China West Normal University. NanChong 637009, Sichuan, China

\begin{abstract}
Adopted the methods of literature investigation, tape-record-statistics, expert interviews, etc, this study conducted the technique statistics and analysis on the video of the competition of the Guangdong and Tianjin woman volleyball teams in 2012-2013 National Women Volleyball League Finals. The Game Rhythm advantages and disadvantages of Guangdong and Tianjin woman volley-ball teams were proposed, in order to provide some reference and help the training of National Women Volleyball League competition and china Women Volleyball for the future.
\end{abstract}

Keywords: 2012-2013 national women volleyball game, game rhythm, technique statistics, women volleyball league competition.

\section{INTRODUCTION}

Motor rhythm is a kind of phenomenon demonstrated in the development progress of all natural things [1], it is also a Regular periodic action form of fast and slow, strong and weak, long or short spacing interval, and it is Integral distribution of momentum in space-time. Motor rhythm is reflected by transaction and contrast of speed, power, frequency, amplitude, movement and element in space-time. As we all know, in sporting events, athletes often control their movement through the rhythm of movement, to stabilize one's own mental state, to Reasonable play technology, or by changing the rhythm of movement techniques to achieve destruction of the opponent's mental state competition, disrupt the opponents action technology, so as to achieve gamewinning goal [2]. Therefore, the rhythm has become a campaign on winning the contest to win one of the main guiding principles, especially in the skills of its dominant role in the sport class and value is particularly prominent [3].

Playing Volleyball needs high skills, with the rule triple hitting the ball over the net, especially in the defensive the whole new era of success, it is clear that whatever kind of skill and strategy the athletes take, the rhythm is throughout the entire process, and the rhythm is very clear. Meanwhile, there is no clear boundaries between offense and defense, a good defense often turned out to be a defensive attack, therefore, in volleyball game, one who can reasonably control the game's offensive and defensive rhythm or reasonably change offensive and defensive rhythm, will be able to get the initiative in the game, take the initiative to create a game opponent difficulty to adapt to break the opponent's offensive rhythm or tempo to gain victory [4].
Since 1980's, China women's volleyball team basically represents the development direction of the world women's volleyball team level, in the development of competitive sports, under the influence of "National System", China's women's volleyball league is of world-class level. In 20122013 Volleyball League, the Guangdong team and Tianjin team rushed into the finals by 16:2 and 15:3 respectively. So, in order to further improve the level of China's women's volleyball league and increase our uncertainty of a certain role, I tried to make a comparison of the rhythm in the final of Guangdong and Tianjin women's volleyball team, and I'm willing to provide suggestion to Chinese women's volleyball team training ideas and training of mind adjustment, and through training to achieve a more comfortable grasp and control the pace of the game.

\section{USE RESEARCH OBJECT AND METHOD}

\subsection{Research Object}

In this paper, three matches between women's volleyball

Tianjin and Guangdong team in 2012-2013 season are studied.

\subsection{Research Method}

Literature data method: Through various journals and network information to fully understand some of the indicators which can reflect the rhythm of volleyball competition, and got access to relevant research, provide a more solid theoretical basis for real in the process of this study.

Expert interviews: By interviewing part of volleyball experts or coaches at home and abroad through telephone or letter, talking about the rhythm of the volleyball competition of the reasonable control or rhythm changes in the volleyball competition and the importance as well as the reasons, and consulting rhythm of the different stages of the division race 
Table 1. Serve rhythm and scoring comparison of Guangdong and Tianjin women's volleybal.

\begin{tabular}{|c|c|c|c|c|c|c|c|}
\hline Team & $\begin{array}{c}\text { Score/Average } \\
\text { Rhythm (s) }\end{array}$ & $\begin{array}{c}\text { Loss/Average } \\
\text { Rhythm (s) }\end{array}$ & $\begin{array}{c}\text { Serve Average } \\
\text { Rhythm (s) }\end{array}$ & $\begin{array}{c}\text { Average } \\
\text { Rhythm (s) }\end{array}$ & $\begin{array}{c}\text { The Fastest } \\
\text { Rhythm (s) }\end{array}$ & $\begin{array}{c}\text { The Slowest } \\
\text { Rhythm(s) }\end{array}$ & $\begin{array}{c}\text { Tempo changes (N)/ } \\
\text { Score/Tempo } \\
\text { Change Scoring } \\
\text { Rate (\%) }\end{array}$ \\
\hline \hline Guang dong & $22 / 0.72$ & $28 / 0.69$ & 0.87 & 0.91 & 0.58 & 1.48 & $57 / 32(56.14)$ \\
\hline $\begin{array}{c}\text { Tian } \\
\text { jin }\end{array}$ & $20 / 0.74$ & $24 / 0.71$ & 0.92 & 0.92 & 0.61 & 1.56 & $72 / 56(77.78)$ \\
\hline
\end{tabular}

for a consultation which can reflect the volleyball competition.

Observation statistics: Use screen recorder to record the object of study, based on repeated observation and recording the results of the related statistics. To minimize the statistical error, we two or three persons do the statistics at the same time, and repeated screening and statistical analysis, removing a maximum and a minimum value, and finally take numerical results as the statistical average.

Mathematical statistics method: Obtained processing data by using SPSS.

\section{RESULTS AND ANALYSIS}

\subsection{Analysis and Comparison of Serve Rhythm}

Driving rhythm is the time between the service and the opponent's first time touching the volleyball. At a high level of volleyball game, the serve is often the primary means of scoring, a high quality serve not only threatens the opponent's first passer but also disrupts the rhythm of the opponent's defense attack, and sometimes can score directly. Therefore, the driving rhythm and pace of change commendably influence and determine the overall pace of the game. Table 1 shows, in our 2012-2013 Women's Volleyball League final, first of all, Guangdong women's volleyball ace rhythm, rhythm of losing serve, the general pace of the serve, the fastest pace, slowest pace and rhythm of the overall average are faster than those in Tianjin women's volleyball team, this thus shows the strength of the tee and speed of Guangdong women's volleyball is greater or faster than those in the Tianjin women's volleyball team, we also can say the Guangdong Women's Volleyball team's after ball flight distance, flight speed and range are weaker than Tianjin Women's Volleyball team's after ball [5].

By viewing the gains and losses from the tee points, the Guangdong team score 22 points through the ball, Tianjin's is 20 points, therefore, it can be seen scoring through a relatively faster pace ace is better than the relatively slow-paced ball. Meanwhile, looking at scores from the fault, Guangdong team lost 28 points, Tianjin team lost 24 points, which indicates the possibility of sub-fault increases with the quickening pace of the serve; Secondly, a change of pace from the tee times and changes in score by driving statistics situation in the final, in the three games Guangdong Women's Volleyball serve a total of 57 times of tempo changes, and get a score of 32, driving rhythm of change score rate of $56.14 \%$, Tianjin women's volleyball serve the number of rhythm changes for 72 times, and get a score of
56 , driving rhythm of changing score was $77.78 \%$, from the statistical results we can see, in the 2012-2013 Women's Volleyball League final in China, Tianjin women's volleyball serve obtained significantly higher scores than the Guangdong team by changing the rhythm and the ability.

\subsection{Tactics Rhythm Analysis and Comparison}

The so-called tactical rhythm mainly refers to time allocation between the different rhythm or speed of the first pass, second pass and third pass for the offensive or defensive tactics of a volleyball game. Take Europe and America volleyball, based on "height and power", their winning way is through tactical rhythm of slow pass of the between the first and second pass, and fast third hit, and so on. Therefore, we can say that the tactics in volleyball, speed is an important form of expression and the training element of the corresponding technical, tactical action, between man and the ball's "speed contrast" of or throughout the process of actual events by corresponding to "group rhythm section", if we are good at making other inappropriate use of "group rhythm section" it will lead the development direction of volleyball competition. In China women's volleyball league finals in 2012-2013, Average time of first pass of Guangdong and Tianjin Women's Volleyball was $1.28 \mathrm{~S}$ and $1.30 \mathrm{~S}$, for the second pass, the average time was $0.45 \mathrm{~S}$ and $0.35 \mathrm{~S}$ respectively, the third hit average time is $0.42 \mathrm{~S}$ and $0.47 \mathrm{~S}$ (detailed in Table 2), from the data, rhythm of the first pass of Tianjin, Guangdong team have no significant difference, remains the same or slightly lower with the world women's volleyball, the second pass of Tianjin team is faster than that in Guangdong team and reached the world's best women's volleyball team's fast-paced levels [6], on the third strike, there was no significant difference between the two teams, and achieve a fast paced world elite level, therefore, take a view of the whole rhythm tactics, Tianjin team owns a "slow - fast - fast" group-based rhythm section, while the Guangdong team is of "slow - slow - fast" rhythm section group type; Secondly, from the rhythm and the success rate score tactical point of view, Guangdong team score is 154 of which success rate of $56.41 \%$; Tianjin team score is 187 of which success rate of $64.26 \%$. Therefore, the "slow - fast - fast" rhythm pattern which Tianjin team used is more conducive to control the pace of the game, or more conducive to the destruction of the opponent's tactical rhythm, the rhythm and the type of tactics and the tactics of today's world women's volleyball consistent rhythm; thirdly, as our previous generation of national women's volleyball team's main setter, Feng Kun is not only China's best setter, but also is one of the best international women's volleyball setters. Especially in the "slow - fast - 
Table 2. Sectional rhythm and scoring comparison of Guangdong and Tianjin women's volleyball.

\begin{tabular}{|c|c|c|c|c|}
\hline Team & $\begin{array}{c}\text { First Pass } \\
\text { Average Rhythm (s) }\end{array}$ & $\begin{array}{c}\text { Setter Average Rhythm } \\
\mathbf{( s )}\end{array}$ & $\begin{array}{c}\mathbf{3}^{\text {rd }} \text { Strike Average } \\
\text { Rhythm (s) }\end{array}$ & $\begin{array}{c}\text { Tactics Rhythm Scor- } \\
\text { ing/Loss/Success Rate (\%) }\end{array}$ \\
\hline \hline Guangdong & $1.28 \pm 0.32$ & $0.45 \pm 0.12$ & $0.47 \pm 0.24$ & $154 / 119 / 56.41$ \\
\hline Tianjin & $1.30 \pm 0.27$ & $0.35 \pm 0.08$ & $0.42 \pm 0.18$ & $187 / 104 / 64.26$ \\
\hline & $\mathrm{P}>0.05$ & $\mathrm{P}<0.05$ & $\mathrm{P}>0.05$ & \\
\hline
\end{tabular}

Table 3. Spike rhythm and scoring comparison of Guangdong and Tianjin women's volleyball.

\begin{tabular}{|c|c|c|c|c|c|}
\hline Team & $\begin{array}{c}\text { Back Attack Aver- } \\
\text { age Time }\end{array}$ & $\begin{array}{c}\mathbf{2}^{\text {nd }} \text { Position Spike } \\
\text { Average Time }\end{array}$ & $\begin{array}{c}\mathbf{3}^{\text {rd }} \text { Position Spike } \\
\text { Average Time }\end{array}$ & $\begin{array}{c}\mathbf{4}^{\text {th }} \text { Position Spike } \\
\text { Average Time }\end{array}$ & $\begin{array}{c}\text { Attack Score/Turnover/ } \\
\text { Success Rate (\%) }\end{array}$ \\
\hline \hline Guang & $1.02 \pm 0.55$ & $0.48 \pm$ & $0.38 \pm$ & $1.23 \pm$ & 0.57 \\
dong & $0.91 \pm 0.46$ & 0.23 & 0.25 & $1.03 \pm$ & $141 / 62 / 69.46$ \\
\hline \multirow{2}{*}{ Tianjin } & $\mathrm{P}>0.05$ & 0.34 & $0.33 \pm$ & 0.19 & $152 / 42 / 78.35$ \\
\hline & & $\mathrm{P}>0.05$ & $\mathrm{P}>0.05$ & $\mathrm{P}<0.05$ & \\
\hline
\end{tabular}

Table 4. Spike rhythm and scoring comparison of Guangdong and Tianjin women's volleyball of the last two councils of each match.

\begin{tabular}{|c|c|c|c|c|}
\hline Team & $\begin{array}{c}\text { Back Attack Average } \\
\text { Time }\end{array}$ & $\begin{array}{c}\mathbf{2}^{\text {nd }} \text { Position Spike Average } \\
\text { Time }\end{array}$ & $\begin{array}{c}3^{\text {rd }} \text { Position Spike Average } \\
\text { Time }\end{array}$ & $\begin{array}{c}4^{\text {th }} \text { Position Spike Average } \\
\text { Time }\end{array}$ \\
\hline \hline $\begin{array}{c}\text { Guang } \\
\text { dong }\end{array}$ & $1.23 \pm 0.58$ & $0.58 \pm 0.34$ & $0.51 \pm 0.36$ & $1.41 \pm 0.67$ \\
\hline Tianjin & $1.03 \pm 0.47$ & $0.47 \pm 0.41$ & $0.35 \pm 0.21$ & $1.13 \pm 0.52$ \\
\hline & $\mathrm{P}<0.05$ & $\mathrm{P}<0.05$ & $\mathrm{P}<0.05$ & $\mathrm{P}<0.05$ \\
\hline
\end{tabular}

fast" pace of today's tactics in the Asian women's volleyball team, Feng Kun is fully capable of playing a "slow - fast fast" tactical pace, but why we can only get the opposite result, in my opinion, from the statistics and the competition live and video playback, the first passer's weakness in grasping the opportunity of Guangdong team is a reason which leads to Tianjin team is relatively slower.

\subsection{Spike Rhythm Analysis and Comparison}

Spike is the primary means of scoring, in every game, the smash points are far beyond the other scoring methods, different tactical coordination is made of different smash means, different tactics with the rhythm reflects the different teams technical and tactical characteristics, and its speed directly determines the pace of the game. Though tactical coordination reflects the technical and tactical characteristics of a team, but the effect is often reflected in the third shot, so the rhythm of the third hitting is often influenced by the first and second pass, the impact of rhythm in turn affect the rhythm of a an offensive and defensive, or even the result. As in volleyball, the third batting in the spike of attacks is generally completed form, so athletes in different locations through the rhythm of spike characteristics can reflect the team's tactics with the rhythm. As can be seen in Table 3, Guangdong and Tianjin women's volleyball team's after at- tack, the 2nd position and 3rd position on the spike have no significant difference in the rhythm, but the No.4 position in the smash from the Tianjin team is faster than the Guangdong team, and has a significant difference. This can be related to the Guangdong team outside hitter "holding high hit" on the tactical features, resulting in relatively slow spike, therefore, makes it easier to adapt to this spiking rhythm of each other and form a stable outside hitter block defense tactics, it also shows the Guangdong is team too dependent on outside hitting, or women's volleyball team in fourth place in Guangdong is not strong or inadequate. The other team in Guangdong and Tianjin team's offensive success and failure and the success rate on spike, spike team in Tianjin, Guangdong success rate significantly is higher than the team (detailed in Table 3 ), the data also consistent with the results of the analysis.

At the same time the acquisition and maintenance of spike rhythm has a great relationship with the physical ability of athletes, that athletes are athletes, physical condition is the guarantee for the maintain and change of the spike rhythm. Obviously, the spike is an intensive motor skills exercise, therefore, I took Guangdong and Tianjin team's rhythmic changes for comparison, individually to every game after spiking rhythm of the two Councils have been studied. As can be seen in Table 3, Guangdong women's 
volleyball team after every game, whether the two Councils the average time in the backcourt, offensive, or second pass, third pass and the fourth pass on the spike, the average time is longer than Tianjin women's volleyball team (specific data in Table 4), as the statistical time is the time between the second pass and the touching of the setter, therefore, this result reflects the take-off, spike time, and setter outgoing ball of route length, route and a reasonable ball movement Guangdong women's volleyball do extend the spike time, and these possibilities are greatly related to the physical fitness of athletes, so due to their continuous physical ability Guangdong volleyball players can be able to make the spike longer.

\section{CONCLUSION AND SUGGESTION}

Volleyball team has a faster-paced than Tianjin women's volleyball team, which shows that Guangdong women's volleyball team's serve speed or driving force is greater than that in Tianjin women's volleyball team. Meanwhile, Guangdong Women's Volleyball team's Fault rate is higher than Tianjin women's volleyball team. Good or bad Service quality can often break the opponent's first pass, thereby disrupting the rhythm of the opponent's defense attack, and even can get points through high-quality service, so powerful jump serves can often be seen in modern women's volleyball competition, but the rule of winning a point every dead ball also leads to a lot of missed services. "Returns with risk", therefore, the volleyball team should analyze the situation before serving and should not to take the risk beyond its own ability.

No significant difference in the rhythm of the first pass of Guangdong and Tianjin team, the time remains the same or slightly lower with the world women's volleyball, and rhythm in the second pass on the Tianjin team is faster than the Guangdong team and reached to the world's best women's volleyball team's fast-paced levels, no significant difference between the two teams demonstrated on the third strike, and achieve a fast paced world elite level. Therefore, from The whole rhythm tactics, Tianjin team owns a "slow fast - fast" group-based rhythm section, while the Guangdong team are "slow - slow - fast" rhythm section group type, and Guangdong team-based rhythm section mainly comes from the poor first pass, so the Guangdong team should strengthen cultivation and training of the first passer to change the rhythm section.

"Slow - fast - fast" rhythm pattern is more conducive to control the pace of the game and the destruction of the opponent's tactical rhythm, and Maintains consistency with today's world women's volleyball rhythm. Therefore, all sports teams of China's women's volleyball league in the future, should be strengthened with group rhythm section, the concept of rhythm training, even can be a reference to our national team volleyball.

Spike rhythm of back attack, right sideline, third position and outside hitter of Tianjin women's volleyball team has no significant difference compared to Guangdong a, but the outside hitter's spike is faster than the Guangdong team, and has a significant difference, which is related to "holding a high hit" tactical feature of the outside hitter of Guangdong team, resulting in relatively slow spike, it also shows the Guangdong team is too dependent on outside hitter's attack or the Guangdong Women's Volleyball position is not strong substitutes or inadequate. Therefore, the Guangdong team should strengthen the offensive training of outside hitter, and constantly change her offensive rhythm, or enhance the ability of her.

As strength and tolerance of Guangdong women's volleyball athletes is worse than Tianjin's, in the last two matched of the game, attack average time of back attack, spike average time of right sideline, third position of outside hitter of Guangdong athletes volleyball are longer than Tianjin's, leads to a failure in reasonable controlling the best offence opportunity. Therefore, Guangdong women's volleyball players should improve physical sustainability to better compete against Tianjin women's volleyball team in the future.

\section{CONFLICT OF INTEREST}

The authors confirm that this article content has no conflict of interest.

\section{ACKNOWLEDGEMENTS}

Declared none.

\section{REFERENCES}

[1] Zhang Jumin.Men. Basketball offense rhythm comparative study of the 28th Olympic games[J].China sports science,2005,41(5):61-63.

[2] Ma Li, Tian Wenbin. Development and breakthrough of sports rhythm study.[J].Journal of Beijing Sport University, 2007,30(4):558-559.

[3] A.Leonov, Xue Jingrui. Rhythm is the basement of victory[J].Shandong sports science,1985,(1):25-28.

[4] Yan Bingfeng. Comparative study of Chinese and foreign women volleyball game rhythm[J].Journal of Shandong Normal University,2008,23(4):165-166.

[5] Liu Jianhe. Theoretical Trace on Rhythmic Problems in the Athletic Game [J].Journal of Chengdu sports institute,2002,28(5):64-65.

[6] Li Kesen. Comparative study of Chinese and foreign women volleyball game rhythm[D].Shandong Normal University,2007:12.

Received: September 22, 2014
C Pu and Xiao; Licensee Bentham Open.

Revised: November 30, 2014

Accepted: December 02, 2014

This is an open access article licensed under the terms of the Creative Commons Attribution Non-Commercial License (http://creativecommons.org/licenses/by-nc/3.0/) which permits unrestricted, non-commercial use, distribution and reproduction in any medium, provided the work is properly cited. 